\title{
PROPOSTA DE SEQUÊNCIA DIDÁTICA SOBRE A PRODUÇÃO DE BIOCOMBUSTÍVEIS E SEUS IMPACTOS AMBIENTAIS COM O ENFOQUE CTSA
}

Fernanda Dias da Silva, Universidade Federal de Campina Grande, Cajazeiras - PB $\underline{\text { soufernandadias@gmail.com }}$

Alaim Timóteo Albuquerque, Universidade Federal de Campina Grande, Cajazeiras - PB alaimquimica.ufcg@gmail.com

Geovana do Socorro Vasconcelos Martins, Universidade Federal de Campina Grande, Cajazeiras - PB

geovanasvm@yahoo.com

PALAVRAS-CHAVE: Sequência Didática, Bicombustíveis, Materiais alternativos.

\section{INTRODUÇÃO}

O biodiesel é um substituto natural do diesel de petróleo e pode ser produzido a partir de fontes renováveis como óleos vegetais, gorduras animais e óleos utilizados para cocção de alimentos (fritura) (RAMOS, 2003). Podendo assim tornar-se uma excelente alternativa para o combate a poluição ambiental em que vivemos.

Como se não bastasse, a poluição do ar, as mudanças climáticas e a geração de resíduos tóxicos resultantes do uso do diesel e de outros derivados de petróleo têm um significativo impacto na qualidade do meio ambiente (HOLANDA, 2004). O biodiesel é um combustível biodegradável derivado de fontes renováveis estimuladas por um catalisador, elas reagem quimicamente com álcool formando um produto bifásico, o biodiesel e a glicerina. Existem diferentes espécies de oleaginosas no Brasil que podem ser usadas para produção do mesmo, entre elas estão: A mamona; Dendê; Cânula; Girassol; Amendoim; Soja; o algodão e Matérias-primas de origem animal, como o sebo bovino e gordura suína. Esse bicombustível proporciona ao nosso País uma grande economia com relação a sua importação, além de reduzir a poluição ambiental e gerar varias alternativas de empregos em lugares com pouca atividade econômica, promovendo assim à inclusão social em comunidades carentes com a disponibilização de energia elétrica e fazendo a promoção da inclusão digital considerada atualmente um dos maiores meios de comunicação, o acesso a bens, serviços, informações entre outros. 
De acordo com Ramos et. al. (2006), existem basicamente quatro processos aplicados para a fabricação de biodiesel: Diluição, micro-emulsificação, pirólise e transesterificação que é o mais conhecido e utilizado em larga escala. Por transesterificação entende-se ser o processo químico que consiste em misturar o óleo com o álcool, metanol ou etanol e, na presença de catalisador, hidróxido de sódio ou hidróxido de potássio reage produzindo ésteres metílicos (quando da utilização de metanol) ou ésteres etílicos (quando da utilização de etanol) compondo o biodiesel e a glicerina. Para MURPHY, 1995, quimicamente, transesterificar significa tomar uma molécula de um triglicerídeo ou um ácido graxo complexo, neutralizar os ácidos graxos livres, remover a glicerina e criar um éster.

Este trabalho tem a finalidade de propor destinos ambientalmente corretos para os óleos de frituras antes descartados nas pias de cozinhas, e incentivar a prática de sustentabilidade, indicando as vantagens que são geradas diretamente e indiretamente com o descarte correto do mesmo, através de uma sequência didática aplicada a alunos de uma turma do segundo ano do ensino médio da Escola Estadual José Nilson Santiago na Cidade de Poço Dantas-PB, sob a orientação do Professor Alaim Timóteo Albuquerque, demonstrando a produção de um experimento investigativo intitulado "a produção do biodiesel com materiais alternativos", e posteriormente aplicando-se um questionário para avaliar o grau de aprendizagem dos alunos após a aula.

\section{METODOLOGIA}

Inicialmente elaborou-se uma sequência didática que foi aplicada a numa turma do segundo ano do ensino médio da Escola Estadual José Nilson Santiago na Cidade de Poço Dantas-PB, sob a orientação do Professor Alaim Timóteo Albuquerque, para tanto aplicou-se um experimento investigativo intitulado "a produção do biodiesel com materiais alternativos" buscando incentivar e conscientizar os alunos sobre a reutilização e descarte de óleos de frituras e sobre o desenvolvimento da história do biodiesel no decorrer dos anos. Em seguida foi aplicado um questionário composto por cinco questões de múltipla escolha para avaliar o grau de aprendizagem dos alunos após a aula.

Materiais e reagentes do experimento

Hidróxido de sódio; Álcool; Óleo de frituras; 
01 pote de sorvete (vazio); 01 vidro de maionese; 01 funil; 01 recipiente grande com tampa;

01 colher de chá; 01 copo de alumínio; 01 copo de liquidificador; 06 vidros de detergentes vazios.

\section{Metodologia do experimento}

Adicione ao vidro de maionese uma colher de chá de hidróxido de sódio; em seguida adicione 400ml de álcool ao hidróxido; feche o vidro de maionese e agite bem até a dissolução completa dos grânulos de hidróxido de sódio; ferva 1L de óleo; adicione o óleo ainda quente a um recipiente vazio e com tampa; adicione o metóxido de sódio no recipiente com óleo; agite a solução durante 2 a 3 minutos; deixe sair os vapores de metanol (não respire) que se desenvolvem e fazem inchar o recipiente; transfira a solução para vidros de detergentes; utilizando um pote de sorvete como estante, deixe-os em repouso por algumas horas; faça a separação da glicerina do biodiesel.

\begin{tabular}{|l|l|}
\hline Número de aulas/minutos & 02 aulas/100 minutos \\
\hline Atividades desenvolvidas & $\begin{array}{l}\text { Levantamento das idéias prévias dos alunos. Apresentação da histórica do } \\
\text { Biodiesel e de como obtê-lo através dos óleos de frituras. Discussão a respeito da } \\
\text { atividade experimental. Explicação dos princípios científicos do Biodiesel } \\
\text { alternativo. Aplicação de exercício de fixação. }\end{array}$ \\
\hline Objetivos das atividades & $\begin{array}{l}\text { Compreender a forma correta de se descartar óleos de frituras, e seus impactos na } \\
\text { natureza. A importância do Biodiesel para a sociedade e para o meio ambiente. } \\
\text { Promover a socialização, análise e avaliação das informações apresentadas. }\end{array}$ \\
\hline Principais temas & $\begin{array}{l}\text { Apresentação da histórica do Biodiesel descarte de óleos de frituras, seus } \\
\text { principais impactos ao meio ambiente, tratamento do óleo, uso do Biodiesel no } \\
\text { cotidiano das pessoas. Obtenção de Biodiesel através de óleos de frituras, com } \\
\text { materiais alternativos. }\end{array}$ \\
\hline Ações dos Participantes & $\begin{array}{l}\text { Inicialmente os alunos terão conhecimento a respeito do procedimento } \\
\text { experimental, seus princípios científicos, seus cuidados e sua importância para o } \\
\text { meio ambiente. Em seguida será feita a resolução de exercício com relação ao } \\
\text { conteúdo apresentado aos mesmos. }\end{array}$ \\
\hline
\end{tabular}

Quadro: Sequência Didática: Fonte dos Próprios autores.

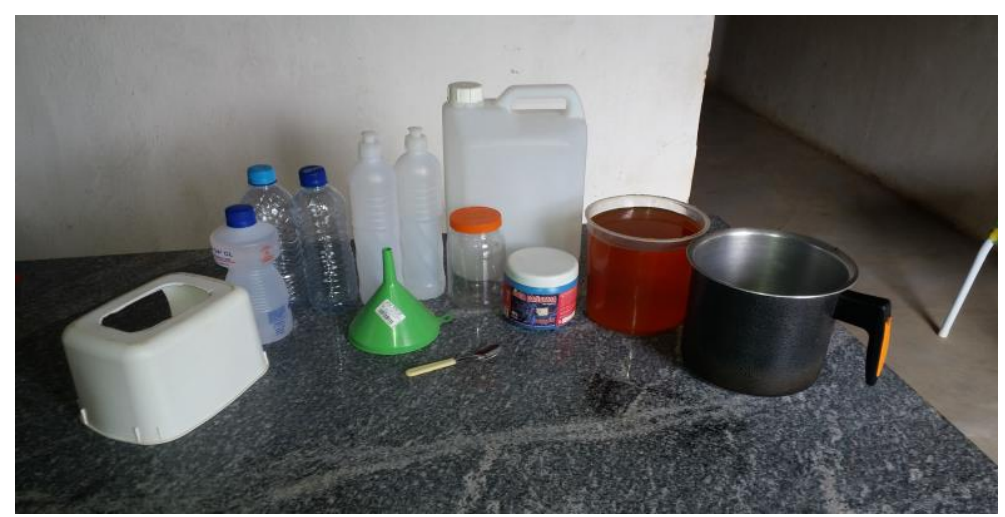

Materiais Utilizados: Fonte dos Próprios autores.

Revista de Pesquisa Interdisciplinar, Cajazeiras, n. 2, suplementar, p. 770 - p. 776, set. de 2017. 

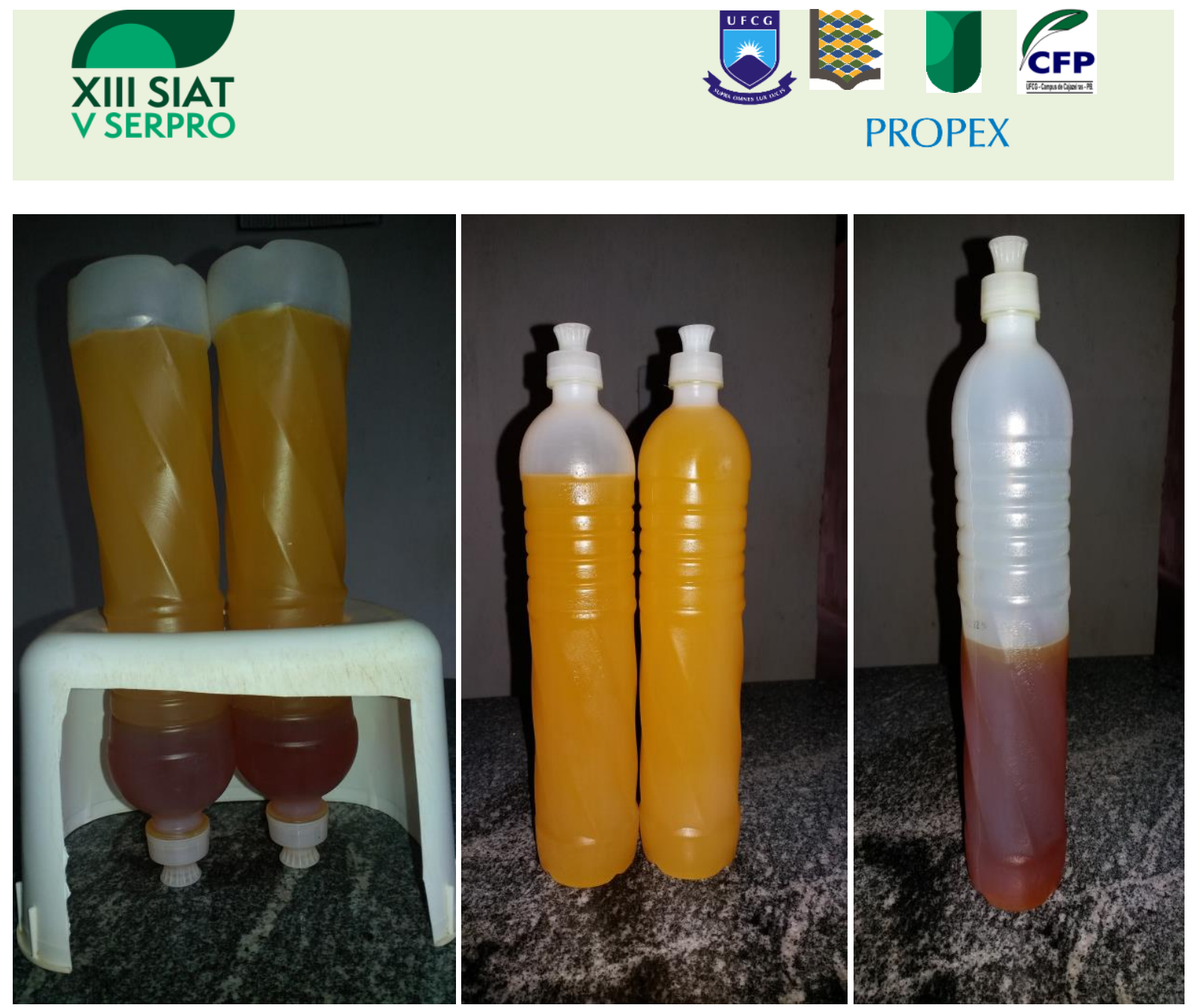

Foto 1. Solução pronta pra ser separa.

Foto 2. Biodiesel Produzido.

Foto 3. Glicerina produzida.

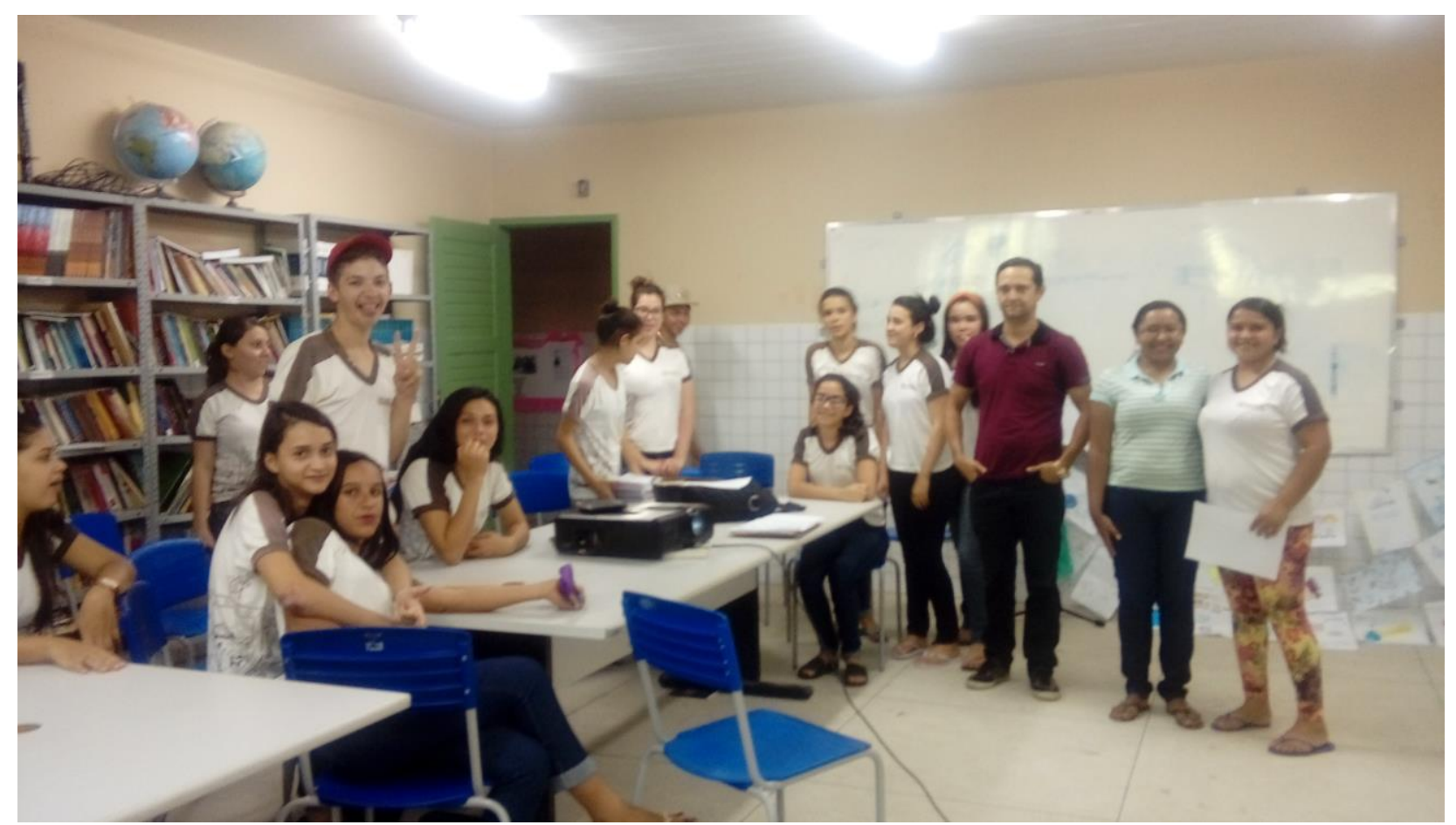

Foto da turma respondendo ao questionário. Fonte dos próprios autores.

Revista de Pesquisa Interdisciplinar, Cajazeiras, n. 2, suplementar, p. 770 - p. 776, set. de 2017. 


\section{RESULTADOS}

Observou-se através do experimento investigativo intitulado "a produção do biodiesel com materiais alternativos" e do questionário aplicado após a aula, que apenas 6 alunos ou cerca de $25 \%$ da turma conhecem as espécies vegetais utilizadas para fabricação do Biodiesel no Brasil, porém em relação ao surgimento do Biodiesel no nosso país, os seus maiores produtores mundiais e a quantidades de indústrias Brasileiras consolidadas e aptas a produzilo, cerca de 24 estudantes, ou seja, 100\% da turma assinalaram as respostas corretas e quando indagados a respeito da aula 11 alunos ou $46 \%$ definiram a aula como boa e 13 alunos ou 54\% relataram que a aula foi ótima.

\section{CONSIDERAÇÕES FINAIS}

Por fim pode-se perceber através dos dados coletados que poucos alunos conhecem todas as plantas oleoginosas utilizadas para a produção do biodiesel tendo em vista que apenas $25 \%$ da turma conheciam todas as espécies, porém cerca de $100 \%$ da turma responderam corretamente as perguntas relacionadas à história do bicombustível no país e seu grau de produção atual através dos seus conhecimentos prévio a respeito do assunto. Do ponto de vista da pesquisa precisa-se avançar a um patamar em que os alunos tenham um conhecimento mais amplo a respeito do descarte correto d óleos de frituras, dos seus impactos ambientais e da real importância da produção de bicombustíveis para a sociedade em geral. 


\section{REFERÊNCIAS}

AGÊNCIA NACIONAL DE PETRÓLEO, GÁS NATURAL E BIOCOMBUSTÍVEIS, DF/ RJ/ SP/ BA, Disponível em (www.ano.gov.br/biocombustível), Agosto de 2010.

HOLANDA, A. Biodiesel e inclusão social. Brasília: Câmara dos Deputados, Coordenação de Publicações, 2004.200p.

MURPHY, M. J.; KETOLA, H. N. \& RAJ, P. K. Summary and assessment of the safety, health, environmental and system risks of alternatives fuels. Helena: U. S. Department of Transportation Federal Transit Administration,

1995. $28 \mathrm{p}$.

RAMOS, L. P.; KNOTHE, G.; VAN GERPEN, J. \& KRAHL, J. Manual de Biodiesel. 1. ed. São Paulo: Edgard Blücher, 2006.

RAMOS, L. P.; KUCEK, C.; DOMINGOS, A. K. \& WILHELM, H. M. Biodiesel: um projeto de sustentabilidade econômica e socioambiental para o Brasil. Brasília: Biotecnologia, Ciência e Desenvolvimento, v.3, p. 28-37, 2003. 
